\title{
Evolutionary radiation of earless frogs in the Andes: molecular phylogenetics and habitat shifts in high-elevation terrestrial breeding frogs
}

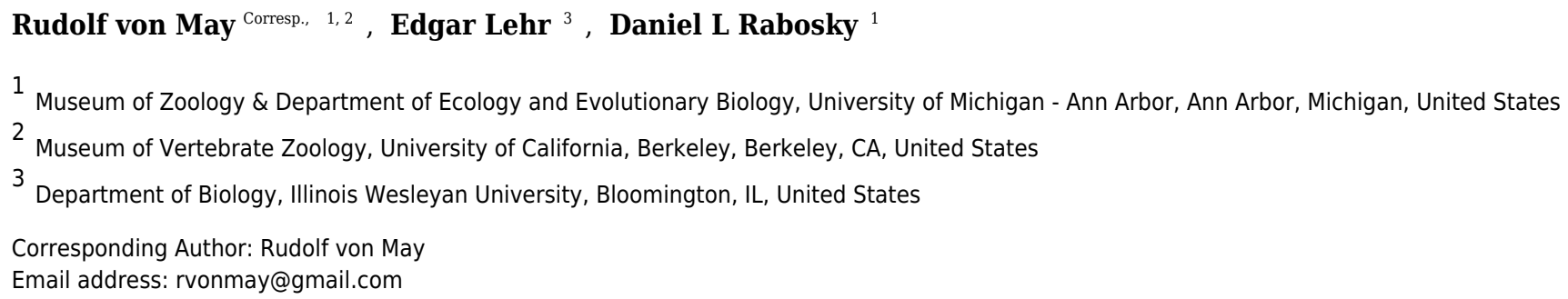

The loss of hearing structures and loss of advertisement calls in many terrestrial breeding frogs (Strabomantidae) living at high elevations in South America are common and intriguing phenomena. The Andean frog genus Phrynopus Peters, 1873 has undergone an evolutionary radiation in which most species lack the tympanic membrane and tympanic annulus, yet the phylogenetic relationships among species in this group remain largely unknown. Here, we present an expanded molecular phylogeny of Phrynopus that includes 24 nominal species. Our phylogeny includes Phrynopus peruanus, the type species of the genus, and 10 other species for which genetic data were previously unavailable. We found strong support for monophyly of Phrynopus, and that two nominal species - Phrynopus curator and Phrynopus nicoleae - are junior synonyms of Phrynopus tribulosus. Using X-ray computed tomography (CT) imaging, we demonstrate that the absence of external hearing structures is associated with complete loss of the auditory skeletal elements (columella) in at least one member of the genus. We mapped the tympanum condition on to a species tree to infer whether the loss of hearing structures took place once or multiple times. We also assessed whether tympanum condition, body size, and body shape are associated with the elevational distribution and habitat use. We identified a single evolutionary transition that involved the loss of both the tympanic membrane and tympanic annulus, which in turn is correlated with the absence of advertisement calls. We also identified several species pairs where one species inhabits the Andean grassland and the other montane forest. When accounting for phylogenetic relatedness among species, we detected a significant pattern of increasing body size with increasing elevation. Additionally, species at higher elevations tend to develop shorter limbs, shorter head, and shorter snout than species living at lower elevations. Our findings strongly suggest a link between ecological divergence and morphological diversity of terrestrial breeding frogs 
living in montane gradients. 
Evolutionary radiation of earless frogs in the Andes: molecular phylogenetics and habitat 2 shifts in high-elevation terrestrial breeding frogs

3

4 5
Rudolf von May ${ }^{1,2}$, Edgar Lehr ${ }^{3}$, Daniel L. Rabosky ${ }^{1}$

${ }^{1}$ Museum of Zoology \& Department of Ecology and Evolutionary Biology, University of Michigan, 2039 Ruthven Museums Building, 1109 Geddes Ave., Ann Arbor, MI 48109, USA

${ }^{2}$ Museum of Vertebrate Zoology, University of California, Berkeley, 3101 Valley Life Sciences Bldg., Berkeley, CA 94720, USA

${ }^{3}$ Department of Biology, Illinois Wesleyan University, P.O. Box 2900, Bloomington, IL 61701, USA

Corresponding author: Rudolf von May, rvonmay@umich.edu 
47

48

49

50

51

52

53

54

55

56

57

58

59

60

61

62

63

64

65

66

67

68

69

70

71

72

73

74

75

76

77

78

79

80

81

82

83

84

85

86

87

88

89

90

91

92

\begin{abstract}
The loss of hearing structures and loss of advertisement calls in many terrestrial breeding frogs (Strabomantidae) living at high elevations in South America are common and intriguing phenomena. The Andean frog genus Phrynopus Peters, 1873 has undergone an evolutionary radiation in which most species lack the tympanic membrane and tympanic annulus, yet the phylogenetic relationships among species in this group remain largely unknown. Here, we present an expanded molecular phylogeny of Phrynopus that includes 24 nominal species. Our phylogeny includes Phrynopus peruanus, the type species of the genus, and 10 other species for which genetic data were previously unavailable. We found strong support for monophyly of Phrynopus, and that two nominal species - Phrynopus curator and Phrynopus nicoleae - are junior synonyms of Phrynopus tribulosus. Using X-ray computed tomography (CT) imaging, we demonstrate that the absence of external hearing structures is associated with complete loss of the auditory skeletal elements (columella) in at least one member of the genus. We mapped the tympanum condition on to a species tree to infer whether the loss of hearing structures took place once or multiple times. We also assessed whether tympanum condition, body size, and body shape are associated with the elevational distribution and habitat use. We identified a single evolutionary transition that involved the loss of both the tympanic membrane and tympanic annulus, which in turn is correlated with the absence of advertisement calls. We also identified several species pairs where one species inhabits the Andean grassland and the other montane forest. When accounting for phylogenetic relatedness among species, we detected a significant pattern of increasing body size with increasing elevation. Additionally, species at higher elevations tend to develop shorter limbs, shorter head, and shorter snout than species living at lower elevations. Our findings strongly suggest a link between ecological divergence and morphological diversity of terrestrial breeding frogs living in montane gradients.

Running head: Evolutionary radiation of earless frogs in the Andes
\end{abstract}

(7)

(8)

8


93

94

95

96

97

98

99

100

101

102

103

104

105

106

107

108

109

110

111

112

113

114

115

116

117

118

119

120

121

122

123

124

125

126

127

128

129

130

131

132

133

134

135

136

137

138

\section{Introduction}

The loss of hearing structures has occurred multiple times throughout the evolutionary history of anurans (Jaslow et al. 1988, Boistel et al. 2013, Pereyra et al. 2016). Multiple losses and regains of the tympanic middle ear in anurans involve the outermost elements of the middle ear, including the tympanic membrane (a thin disk composed of non-glandular skin), the tympanic annulus (a ring composed of cartilage), and, less frequently, the columella (a bone also known as stapes; Vorobyeva \& Smirnov 1987, Pereyra et al. 2016). Within the middle ear cavity, the outermost portion of the columella is in contact with the inner wall of the tympanic membrane and aids in the transmission of airborne vibrational signals to the inner ear (Mason et al. 2015). Earlessness (i.e., the loss of tympanic middle ear structures) is particularly common in some groups such as the true toad family Bufonidae, which contains over 200 earless species (Pereyra et al. 2016) or approximately $30 \%$ of the total species richness of this group (607 species; AmphibiaWeb 2017). In South America, the absence of tympanic membrane and tympanic annulus is also common in the terrestrial breeding frog family Strabomantidae (Hedges et al. 2008, Padial et al. 2014) and is particularly prevalent in several clades distributed at high elevations (e.g., Bryophryne, Phrynopus; Duellman \& Lehr 2009). How these frogs communicate and what factors drove the loss of hearing structures at high elevations are questions that remain unexplored in this diverse group of amphibians.

Given that the tympanic middle ear has been lost multiple times in the evolutionary history of anurans, including complex patterns of loss and regain in some large radiations (e.g., bufonids; Pereyra et al. 2016), it is relevant to examine how the loss of tympanic middle ear structures is distributed across other less known but equally diverse radiations such as Strabomantidae. Understanding the potential causes and ecological consequences of repeated losses and occasional regains of a character across a phylogenetic tree could be useful to infer patterns of morphological and ecological diversity in this group. Within this family, the Andean frog genus Phrynopus (Figure 1) represents a special case where the large majority of species $(>90 \%)$ have lost the tympanic membrane and tympanic annulus. Members of this clade inhabit montane forests and Andean grasslands (also known as Puna) at elevations between 2600 and $4490 \mathrm{~m}$ (Duellman \& Lehr 2009, Lehr et al. 2017, Rodríguez \& Catenazzi 2017), and share morphological features with other high elevation strabomantids in the genera Bryophryne, Pristimantis, Lynchius, and Oreobates (Lehr \& von May 2017). Given that the Andes have experienced multiple uplift events since the Miocece (Gregory-Wodzicki 2000), the resulting combined effects of habitat, elevation, and climatic gradients played an important role in species' ecological divergence along montane gradients (Moritz et al. 2000, Rheindt et al. 2008, Antonelli et al. 2009, Irestedt et al. 2009, von May et al. 2017) and may have also influenced the morphological diversity of terrestrial breeding frogs observed today.

The genus Phrynopus currently contains 34 species distributed in the Peruvian Andes (Lehr \& Rodríguez 2017, Rodríguez \& Catenazzi 2017). From these, only three species exhibit a tympanic membrane and tympanic annulus whereas the remaining 31 species lack both structures (we refer to these as earless species, i.e., those with no tympanic membrane and no tympanic annulus). Additionally, only the eared species are known to produce advertisement calls (i.e., earless species do not produce calls; Duellman \& Lehr 2009; E. Lehr and R. von May, personal 
139 observations). In contrast, in other anuran families that contain lineages that lost the tympanic 140 middle ear, most of those lineages typically retained the ability to call and species evolved alternative extra-tympanic sensory pathways that enable the transmission of low frequency sound to the inner ear (e.g., Bombinatoridae, Hetherington \& Lindquist 1999; Brachycephalidae, Goutte et al. 2017; Bufonidae, Pereyra et al. 2016, Womack et al. 2017; Sooglossidae, Boisel et al. 2013). While the actual mode of communication in the 31 earless species of Phrynopus is currently unknown, it is valuable to examine the presence and absence of tympanic middle ear structures in a phylogenetic framework to understand if the loss of hearing structures took place once or multiple times in this clade. Speciation in the absence of common acoustic signals in frogs, such as the one observed in Phrynopus, raises questions about the factors that affect speciation given that advertisement calls are recognized as a premating isolation mechanism (Boughman 2002).

151

Here, we present an expanded molecular phylogeny of Phrynopus that contains 53 terminals representing 24 species. We inferred a species tree, and we used this tree to examine the relationship between species' morphological features and their elevational distributions in a phylogenetic comparative framework. To determine whether key skeletal traits (columella) were lost, in addition to other tympanic structures that are observable with a dissecting scope, we used $\mathrm{X}$-ray micro-computed tomography $(\mu \mathrm{CT})$ to obtain images for one eared and one earless species. Phrynopus comprise a radiation lacking both the communication signal (advertisement calls) and sensory system (tympanic membrane and annulus) typical to the large majority of anurans. Previous studies focusing on other anuran taxa have shown that earless species live in diverse habitats and may experience different selection pressures, suggesting that the loss of tympanic middle ear is not associated with a particular environment (Vorobyeva \& Smirnov 1987, Smirnov 1991, Womack et al. 2017). Overall patterns of habitat use and elevational distribution of Phrynopus also seem to support this idea, but proper testing is required.

Given that terrestrial breeding frogs living at high elevations experience different ecological conditions than those living at lower elevations (Catenazzi et al. 2014, von May et al. 2017), they may also experience different selection pressures promoting morphological diversification. To test this hypothesis, we examined if body size and body shape vary across habitats or elevations. Several studies have suggested that larger body size in Neotropical terrestrial breeding frogs might represent an adaptation to high-elevation habitats (Hedges et al. 1999, Gonzalez-Voyer et al. 2011). Given that species living in high-elevation habitats such as the Andean grassland appear to have larger body and different body shape than species living at lower elevations (Lehr \& von May 2017), we hypothesized that body size and body shape are associated with the type of habitat use and elevation. These direct-developing frogs are amenable for testing this hypothesis because they have low vagility (resulting in local genetic structuring) and in most cases limited geographic and elevational ranges (Duellman \& Lehr 2009, De la Riva et al. 2017, von May et al. 2017). A larger body size at higher elevations would agree with Bergmann's rule, which predicts that body size increases in cooler environments (Bergmann 1847, Mayr 1956); this pattern requires further testing because it is not universal among amphibians (Adams \& Church 2007). We did not expect to observe different morphologies between eared and earless species, because the absence of tympanic middle ear in Phrynopus is not associated with a particular environment (Duellman \& Lehr 2009). 
185 The first molecular phylogeny of Phrynopus (Lehr et al. 2005) included eight currently

186 recognized species in addition to five other species that were subsequently transferred to

187 different genera (e.g., Phrynopus iatamasi was transferred to the genus Psychrophrynella by

188 Hedges et al. 2008, and it was subsequently transferred to the genus Microkayla by De la Riva et

189 al. 2017). Hedges et al. (2008) inferred that Phrynopus is a close relative of the clades composed

190 of Lynchius and Oreobates, a result corroborated by Padial et al. (2014). Both Hedges et al.

191 (2008) and Padial et al. (2014) included sequences of 11 species of Phrynopus in their analyses.

192 More recently, a molecular phylogenetic analysis focusing on Holoadeninae (the strabomantid

193 subfamily that contains Phrynopus) included sequences of 13 species of Phrynopus (De la Riva

194 et al. 2017). De la Riva et al. (2017) reported high genetic similarity between two species, $P$.

195 nicoleae and $P$. tribulosus, and suggested a possible synonymy, but no formal taxonomic action

196 was proposed. Furthermore, none of the previous analyses included Phrynopus peruanus Peters,

197 1873, the type species of the genus, despite the rediscovery and collection of specimens at the

198 type locality (Lehr 2007). Given that multiple taxonomic changes have taken place in this group

199 (e.g., some Phrynopus transferred to Psychrophrynella and subsequently to Microkayla;

200 Phrynopus ayacucho transferred to the genus Oreobates; Padial et al. 2012), it is essential to

201 include the type species in successive phylogenetic analyses such as those presented here.

202

203

204

205

206

207

208

209

210

211

212

213

214

215

216

217

218

219

220

221

222

223

224

225

226

227

228

229

230

\section{Materials and Methods}

Study area and field surveys. We surveyed multiple montane sites between April 2012 and September 2014, and collected specimens and ecological data on 11 species of Phrynopus. The surveyed areas included the type locality of Phrynopus badius Lehr, Moravec \& Cusi 2012, Phrynopus curator Lehr, Moravec \& Cusi 2012, Phrynopus daemon Chávez, Santa-Cruz, Rodríguez \& Lehr 2015, Phrynopus interstinctus Lehr \& Oroz 2012, Phrynopus inti Lehr, von May, Moravec \& Cusi 2017, Phrynopus juninensis (Shreve, 1938), Phrynopus montium (Shreve, 1938), Phrynopus peruanus Peters, 1873, Phrynopus unchog Lehr \& Rodríguez 2015,

Phrynopus vestigiatus Lehr \& Oroz 2012, Phrynopus spI (von May, unpublished). In addition to collecting primary data on these species, we reviewed published studies to assemble a dataset containing minimum and maximum elevation, elevational midpoint, and habitat (Table S1) for those species included in phylogenetic comparative analyses (see below). Research and collecting permits were issued by the Dirección General Forestal y de Fauna Silvestre (DGFFS) and the Servicio Nacional Forestal y de Fauna Silvestre (120-2012-AG-DGFFS-DGEFFS, 0642013-AG-DGFFS-DGEFFS, 292-2014-AG-DGFFS-DGEFFS, R.D.G. No 029-2016-SERFORDGGSPFFS, R.D.G. 405-2016-SERFOR-DGGSPFFS, and Contrato de Acceso Marco a Recursos Genéticos, $N^{\circ}$ 359-2013-MINAGRI-DGFFS-DGEFFS) and the Servicio Nacional de Areas Naturales Protegidas ( ${ }^{\circ}$ 001-2012-SERNANP-JEF). Export permits were issued by the Ministerio del Ambiente, Lima, Peru. Use of vertebrate animals was approved by the Animal Care and Use Committee of the University of California (ACUC \#R278-0412, R278-0413, and R278-0314). Specimens collected during this study were deposited in the herpetological collection at the Museo de Historia Natural Universidad Nacional Mayor de San Marcos (MUSM), Lima, Peru.

Morphological data. We compiled available morphological data for 21 species of Phrynopus included in our phylogenetic analysis (data were not available for Phrynopus sp, an undescribed species from Pasco region, central Peru; Lehr et al. 2017). Most of these data were extracted 
231 from the original publications describing these species (Hedges 1990, Lehr et al. 2000, Lehr

232 2001, Lehr et al. 2002, Lehr \& Aguilar 2003, Lehr et al. 2005, Chaparro et al. 2008, Duellman \&

233 Hedges 2008, Lehr \& Oroz 2012, Lehr et al. 2012, Chávez et al. 2015, Lehr \& Rodríguez 2017,

234 Lehr et al. 2017, Rodríguez \& Catenazzi 2017). Additionally, for three species (P. juninensis, $P$.

235 peruanus, and Phrynopus spI), we took measurements of specimens collected in recent

236 expeditions. Our dataset included only adult individuals $(\mathrm{N}=76)$; for all of these, sex and

237 maturity of specimens were determined by observing gonads through dissections under a

238 stereomicroscope (Table S2; see original species descriptions for further detail). Our dataset

239 included the following measurements: snout-vent length (SVL), tibia length (TL, distance from

240 the knee to the distal end of the tibia), foot length (FL, distance from proximal margin of inner

241

242

243

244

245

246

247

248

249

250

251

252

253

254

255

256

257

258

259

260

261

262

263

264

265

266

267

268

269

270

271

272

273

274

275

276 metatarsal tubercle to tip of Toe IV), head length (HL, from angle of jaw to tip of snout), head width (HW, at level of angle of jaw), horizontal eye diameter (ED), interorbital distance (IOD), upper eyelid width (EW), internarial distance (IND), eye-nostril distance (E-N, straight line distance between anterior corner of orbit and posterior margin of external nares). Information on species tympanum condition was obtained from Duellman and Lehr (2009) and from subsequent species descriptions (Lehr \& Oroz 2012, Lehr et al. 2012, Chávez et al. 2015, Lehr \& Rodríguez 2017, Lehr et al. 2017, Rodríguez \& Catenazzi 2017).

Micro-computed tomography. To determine the condition of the columella, a key element of the tympanic middle ear, we obtained X-ray $\mu \mathrm{CT}$ images for one eared and one earless species, Phrynopus peruanus and Phrynopus montium, respectively. Two voucher specimens stored in ethanol were scanned in the Micro-CT Core facility at the University of Michigan. Specimens were placed in a $34 \mathrm{~mm}$ diameter specimen holder and scanned using a microCT system ( $\mu$ CT100 Scanco Medical, Bassersdorf, Switzerland). Scan settings were: voxel size $11.4 \mu \mathrm{m}, 55$ $\mathrm{kVp}, 145 \mu \mathrm{A}, 0.5 \mathrm{~mm}$ AL filter, 1000 projections around $180^{\circ}$, integration time of $1000 \mathrm{~ms}$ and 3 average data. Data were exported to DICOM files using Scanco's proprietary software. We obtained images after segmentation using isosurface representations and three-dimensional renderings using the Amira-Avizo software. According to the predictions of Pereyra et al. (2016) the presence of tympanic membrane and tympanic annulus in P. peruanus implies that the columella is present. Thus, we expected to observe the columella in a CT scan of $P$. peruanus. In contrast, the absence of both tympanic membrane and tympanic annulus in $P$. montium did not imply that the columella would be absent. Thus, CT scanning this specimen was particularly critical to determine if the columella was present (or not) in this species.

Molecular phylogenetic analysis. Our analysis included DNA sequence data from Phrynopus species that were available in GenBank (as of 1 August 2017; Table S2) as well as sequences from other closely related genera (Lynchius, Oreobates) and more distantly related ones (Ischnocnema guentheri, Hypodactylus brunneus, and Hypodactylus dolops) as outgroups following the results of Padial et al. (2014). Additionally, newly produced sequences include those obtained from 11 species: P. badius, P. curator, P. daemon, P. interstinctus, P. juninensis, P. montium, P. peruanus, $P$. unchog, $P$. vestigiatus, Phrynopus inti, and Phrynopus spI. A notable addition to this phylogeny is $P$. peruanus, the type species of the genus.

The mitochondrial genes were a section of the 16S rRNA gene, a section of the 12S rRNA gene, and the protein-coding gene cytochrome c oxidase subunit I (COI). The nuclear genes were the recombination-activating protein 1 (RAG1) and Tyrosinase precursor (Tyr). Extraction, 
277 amplification, and sequencing of DNA followed protocols previously used for Neotropical

278 terrestrial breeding frogs (Lehr et al. 2005, Hedges et al. 2008). Primers used are listed in Table

279 S3. We employed the following thermocycling conditions to amplify DNA from each gene using

280 the polymerase chain reaction (PCR). For $16 \mathrm{~S}$, we used: 1 cycle of $96^{\circ} \mathrm{C} / 3 \mathrm{~min} ; 35$ cycles of

$28195^{\circ} \mathrm{C} / 30 \mathrm{~s}, 55^{\circ} \mathrm{C} / 45 \mathrm{~s}, 72^{\circ} \mathrm{C} / 1.5 \mathrm{~min} ; 1$ cycle $72^{\circ} \mathrm{C} / 7 \mathrm{~min}$. For $12 \mathrm{~S}$, we used: 1 cycle of $94^{\circ} \mathrm{C} / 1.5$

$282 \mathrm{~min} ; 35$ cycles of $94^{\circ} \mathrm{C} / 45 \mathrm{~s}, 50^{\circ} \mathrm{C} / 1 \mathrm{~min} ., 74^{\circ} \mathrm{C} / 2 \mathrm{~min} ; 1$ cycle $72^{\circ} \mathrm{C} / 10 \mathrm{~min}$. For COI, we used:

2831 cycle of $96^{\circ} \mathrm{C} / 3 \mathrm{~min} ; 35$ cycles of $95^{\circ} \mathrm{C} / 30 \mathrm{~s}, 55^{\circ} \mathrm{C} / 45 \mathrm{~s}, 72^{\circ} \mathrm{C} / 1.5 \mathrm{~min} ; 1$ cycle $72^{\circ} \mathrm{C} / 7 \mathrm{~min}$. For

284 RAG1, we used: 1 cycle of $96^{\circ} \mathrm{C} / 2 \mathrm{~min} ; 40$ cycles of $94^{\circ} \mathrm{C} / 30 \mathrm{~s}, 52^{\circ} \mathrm{C} / 30 \mathrm{~s}, 72^{\circ} \mathrm{C} / 1.5 \mathrm{~min} ; 1$

285 cycle $72^{\circ} \mathrm{C} / 7 \mathrm{~min}$. For Tyr, we used: 1 cycle of $94^{\circ} \mathrm{C} / 5 \mathrm{~min} ; 40$ cycles of $94^{\circ} \mathrm{C} / 30 \mathrm{~s}, 54^{\circ} \mathrm{C} / 30 \mathrm{~s}$,

$28672^{\circ} \mathrm{C} / 1 \mathrm{~min} ; 1 \mathrm{cycle} 72^{\circ} \mathrm{C} / 7 \mathrm{~min}$. We completed the cycle sequencing reactions by using the

287 corresponding PCR primers and the BigDye Terminator 3.1 (Applied Biosystems), and obtained

288 sequence data by running the purified reaction products in an ABI 3730 Sequence Analyzer

289 (Applied Biosystems). We deposited the newly obtained sequences in GenBank (Table S2).

290

291

We used Geneious R6, version 6.1.8 (Biomatters 2013; http://www.geneious.com/) to align the sequences with the built-in multiple alignment program. Prior to conducting phylogenetic analysis, we used PartitionFinder, version 1.1.1 (Lanfear 2012) to select the appropriate models of nucleotide evolution and used the Bayesian information criterion (BIC) to determine the best partitioning scheme and substitution model for each gene. We divided the partitions a priori; each mitochondrial gene was considered a data block whereas each nuclear gene was divided by codon position (i.e., three data blocks per gene). The best partitioning schemes and models of evolution are included in the Results section.

299

300

301

302

303

304

305

306

307

308

309

310

We employed a Bayesian approach using MrBayes, version 3.2.0 (Ronquist \& Huelsenbeck 2003 ) to infer a molecular phylogeny. Our analysis included 72 terminals and a 2646-bp concatenated partitioned dataset. We performed an MCMC Bayesian analysis that consisted of two simultaneous runs of 8 million generations, and we set the sampling rate to be once every 1000 generations. Each run had three heated chains and one "cold" chain, and the burn-in was set to discard the first $25 \%$ samples from the cold chain. Following the completion of the analysis, we used Tracer 1.6 (Rambaut \& Drummond 2003) to verify convergence. Subsequently, we used FigTree (http://tree.bio.ed.ac.uk/software/figtree/) to visualize the majority-rule consensus tree and the posterior probability values to assess node support.

We also used a multispecies coalescent approach implemented in *BEAST v1.6.2 (Drummond \& Rambaut 2007) to infer a species tree to be used for phylogenetic comparative analyses (see

312 below). Our analyses only depend on the relative branch lengths of the tree, but we preferred to

313 illustrate our tree in approximate units of time. Therefore, we used an uncorrelated relaxed

314 molecular clock with the rate of nucleotide substitution for $16 \mathrm{~S}$ set at $1 \%$ per million years as done in a recent study (von May et al. 2017). However, as in von May et al. (2017), we note that the dates associated with the tree should only be viewed as very approximate and that there can be multiple sources of error when calibrating phylogenies (Arbogast et al. 2002). The analysis in *BEAST included two independent runs, each with 100 million generations and sampled every 10000 generations. Following the completion of the analysis, we used Tracer v1.5 (Rambaut \& Drummond 2007) to examine effective sample sizes, verify convergence of the runs, and to ensure the runs had reached stationarity. Observed effective sample sizes were sufficient for most parameters (ESS >200) except for substitution rates for a few partitions. We discarded the 
323 first $10 \%$ of samples from each run as burn-in. Subsequently, we used LogCombiner v1.6.2 to

324 merge all remaining trees from both runs and used TreeAnnotator v1.6.2 (Drummond \&

325 Rambaut 2007) to summarize trees and obtain a Maximum Clade Credibility tree (available at

326 the Dryad Digital Repository: doi pending). We visualized the Maximum Clade Credibility

327 (MCC) tree and the associated node support values in FigTree

328 (http://tree.bio.ed.ac.uk/software/figtree/).

329

330

331

332

333

334

335

336

337

338

339

340

341

342

343

344

345

346

347

348

349

350

351

352

353

354

355

356

357

358

359

360

361

362

363

364

365

366

367

368

Morphological and ecological divergence. We mapped the tympanum condition on to the species tree to infer whether the loss of hearing structures took place once or multiple times. The hypothesized ancestral tympanic condition in Phrynopus along the internal branches of a phylogenetic tree including members of two other closely related genera (Lynchius and Oreobates) was determined using Bayesian stochastic character mapping (Huelsenbeck et al. 2003) implemented in the phytools package (Revell 2012). A mapping of tympanum presence/absence in the phylogeny was run on 500 stochastically mapped trees to take into account the uncertainty in the ancestral tympanum condition.

We also mapped the elevational range on to the species tree to visually assess the patterns of elevational distribution, phylogenetic relatedness, and presence/absence of tympanic membrane and annulus. For visualization purposes, we modified the range of species known from a single elevation or those known from a very narrow range $(<50 \mathrm{~m})$ to cover a minimum elevational band of $80 \mathrm{~m}$. For species known from a single elevation, this elevation was assumed to be the midpoint and this number was used to expand the range on both directions $(-40$ and +40$)$ to be $80 \mathrm{~m}$. This allowed us to plot a color-coded bar representing the main habitat of each species. For species known to cover a narrow elevational band $(<50 \mathrm{~m})$, we first calculated the elevational midpoint (i.e., maximum elevation - minimum elevation) and used this value to expand the range on both directions $(-40$ and +40$)$ to be $80 \mathrm{~m}$. These adjusted ranges were used in only one figure (i.e., original data were used in all other figures and analyses).

Additionally, we examined if body size and body shape vary across habitats or elevations. Given that terrestrial breeding frogs living in high-elevation habitats appear to have larger body size and different body shape than species living at lower elevations (Hedges et al. 1999, GonzalezVoyer et al. 2011, Lehr \& von May 2017), we hypothesized that body size and body shape in Phrynopus are associated with the type of habitat use and elevation. First, we used phylogenetic principal components analysis (PCA) to examine morphological diversity between eared and earless species and among habitats. To remove the possible confounding effect of body size difference among species while controlling for non-independence resulting from shared phylogenetic history, we performed a phylogenetic size-correction using generalized leastsquares (GLS) regression analysis (Revell 2009). In this analysis, we considered SVL as the independent variable and all other morphological data were considered dependent variables. To perform the phylogenetic PCA, we pruned the species tree to only include 21 species of Phrynopus with corrected morphological data. We projected the first two PC axes on a phylomorphospace using the function phylomorphospace in phytools (Revell 2012). We also used a phylogenetic ANOVA (Garland et al. 1993) to quantify shape differences between eared and earless species and to quantify shape differences among habitats. For the latter comparison, we defined three groups (Andean grassland, montane forest, both habitats) and selected a posthoc test to compare means among groups; we used the "holm" method to adjust the P-values 
369

370

371

372

373

374

375

376

377

378

379

380

381

382

383

384

385

386

387

388

389

390

391

392

393

394

395

396

397

398

399

400

401

402

403

404

405

406

407

408

409

410

411

412

413

414

to account for multiple comparisons. These analyses were also implemented using phytools.

We used a scatterplot pairwise matrix to examine the relationships among body size, other body size-corrected morphometric variables, and elevation. We used the R package 'phylolm' (Ho \& Anné 2014ab) to fit phylogenetic generalized linear regression models (PGLS), implemented under three models of evolution: (a) pure ordinary least squares (OLS) regression (i.e., no phylogenetic signal), (b) pure Brownian motion (BM) model, and (c) lambda transform model, which allows intermediate levels of phylogenetic signal between pure BM and pure OLS (we reported Pagel's lambda coefficient, $\lambda$, for the third model). We used the AIC value to identify the model that best explains the variation in observed data (Ho \& Anné 2014b).

\section{Results}

Micro-computed tomography. We visualized tree-dimensional reconstructions of X-ray $\mu \mathrm{CT}$ images of the skull of the eared taxon Phrynopus peruanus, and confirmed the presence of the columella in this species (Figure 2). In contrast, the columella has been completely lost in the earless $P$. montium (Figure 2). This observation, in combination with previous findings (Trueb \& Lehr 2008), confirms that $P$. montium has lost the three main elements of the middle ear (tympanic membrane, tympanic annulus, and columella).

Molecular phylogenetic analysis. The best partitioning scheme included six subsets (BIC value: 34189.93). The first partition subset included both the $12 \mathrm{~S}$ and $16 \mathrm{~S}$ sequences and the best fitting substitution model was GTR $+\mathrm{I}+\mathrm{G}$. The remaining five subsets were partitioned according to codon positions as follows (substitution model in parenthesis): one set including the $1^{\text {st }}$ codon position of COI $(\mathrm{K} 80+\mathrm{I})$, one set including the $2^{\text {nd }}$ codon position of COI $(\mathrm{HKY}+\mathrm{I})$, one set including the $3^{\text {rd }}$ codon position of COI $(\mathrm{GTR}+\mathrm{G})$, one set including the $1^{\text {st }}$ and $2^{\text {nd }}$ codon position of RAG1 and the $1^{\text {st }}$ and $2^{\text {nd }}$ codon position of Tyr $(\mathrm{HKY}+\mathrm{I})$, and one set including the $3^{\text {rd }}$ codon position of both RAG1 and Tyr $(\mathrm{HKY}+\mathrm{G})$. At the end of the MCMC run, the average standard deviation of split frequencies was 0.002538 . We found that Phrynopus is a wellsupported monophyletic group that is closely related to Oreobates and Lynchius (Figure 3). The earliest divergence within Phrynopus occurred between a clade formed by two species, $P$. peruanus and an undescribed species (Phrynopus spI), and all other species. Our analysis suggested that two nominal species, Phrynopus curator and Phrynopus nicoleae, are junior synonyms of Phrynopus tribulosus; a proposed formal taxonomic change is included below (New synonymy).

Phylogenetic relatedness and trait-and-habitat data. We used the species tree obtained with *BEAST to visually assess tympanum presence/absence (Figure 4). Our analysis identified a single evolutionary transition that involved the loss of both the tympanic membrane and tympanic annulus (Figure 4).

We used the species tree to assess the patterns of elevational distribution and phylogenetic relatedness (Figure 5). We observed substantial differences in elevational distribution among closely-related species, with some species pairs occurring in distinct habitats (Figure 5). In four cases, close relatives had non-overlapping elevational distributions (P. peruanus-Phrynopus spI; P. bracki-P. badius; P. miroslawae-P. tautzorum; P. unchog-P. daemon). Additionally, in three 
415 cases, close relatives were associated with either Andean grassland or montane forest $(P$.

416 peruanus-Phrynopus spI; P. barthlenae-P. horstpauli; P. miroslawae-P. tautzorum).

417

418 Our analysis of body-size corrected morphological data showed that Phrynopus species exhibit a

419 considerable variation in body shape. This variation appeared not to be associated with the

420

421

422

423

424

425

426

427

428

429

430

431

432

433

434

435

436

437

438

439

440

441

442

443

444

445

446

447

448

449

450

451

452

453

454

455

456

457

458

459 Phrynopus curator Lehr, Moravec \& Cusi, 2012; p. 63, Figures 5, 7, 8, 10 [MUSM 31106

460 presence or absence of tympanic middle ear structures (Figure 6a, b); instead, species differences in body shape were associated with the habitat they occupy (Figure 6c, d). Specifically, species that live in Andean grassland occupied a smaller area in the phylomorphospace projection that species that live in montane forest or those that occupy the two habitats.

Considering data from all adult specimens (males and females), the first seven principal components were found to explain $97.5 \%$ of the variance within the size-corrected morphological dataset following a phylogenetic size-correction using GLS regression (Table 1). Considering data from female specimens only, the first seven principal components were found to explain $96.7 \%$ of the variance within the size-corrected morphological dataset following a phylogenetic size-correction using GLS regression (Table 2). We found no shape differences between eared and earless species (phylogenetic ANOVA, all tests $\mathrm{P}>0.10$ ). We found that habitat had a significant effect on shape, notably in those variables (FL, HL, HW, IOD, E-N) that had greater contribution on $\mathrm{PC} 2$ (phylogenetic ANOVA, $\mathrm{F}=3.943, \mathrm{P}=0.036$ ).

We used a pairwise scatterplot matrix to visualize the cross-correlations among body-size corrected morphological data, SVL, and elevation (figure S1). Our PGLS analyses showed that there is a significant pattern of increasing body size at higher elevations, and that species living at higher elevations tend to develop shorter limbs, shorter head, and shorter snout than those species living at lower elevations (Table 3, Figure 7). All tested relationships were significant both when controlling for phylogeny under the lambda transform model and also under pure OLS regression, and OLS was the best-supported model in five cases. One relationship, total length vs. elevational midpoint, was best supported under the Brownian motion (BM) model (and it was also significant under both the OLS and Lambda models).

New synonymy. Here we synonymize Phrynopus tribulosus Duellman \& Hedges, 2008 with both Phrynopus curator Lehr, Moravec \& Cusi, 2012 and Phrynopus nicoleae, Chaparro, Padial \& De la Riva, 2008.

\section{Phrynopus tribulosus Duellman \& Hedges, 2008}

Phrynopus nicoleae, Chaparro, Padial \& De la Riva, 2008; p. 53, Figures 5, 6 [MHNC 6441(holotype) collected by J. C. Chaparro, A. Quiroz and D. Salcedo at Santa Bárbara (10 20' 36.3"S, 75 38' 17.9"W; 3589 m a.s.l.), Distrito de Huancabamba, Provincia de Oxapampa, Departmento Pasco, Peru, 2007] — Lehr \& Oroz 2012, p. 55, 59; Lehr et al. 2012, p. 51, 52, 55, 59, 61, 65, 66, Table 1; Padial et al. 2014, p. 124; Chávez et al. 2015, p. 21; De la Riva et al. 2017, p. 5, 31, 44; Lehr \& Rodríguez 2017, p. 333, 334; Rodríguez \& Catenazzi 2017, p. 383, $386,390,399,401,403$, Table 2 . (holotype) collected by E. Lehr, J. Moravec, and J. C. Cusi at Quebrada Yanachaga (10 
461

462

463

464

465

466

467

468

469

470

471

472

473

474

475

476

477

478

479

480

481

482

483

484

485

486

487

488

489

490

491

492

493

494

495

496

497

498

499

500

501

502

503

504

505

506

22.772'S, $75^{\circ} 27.717^{\prime} \mathrm{W} ; 3000$ m a.s.1.), Yanachaga-Chemillén National Park (Sector San Daniel), Distrito de Huancabamba, Provincia de Oxapampa, Departamento de Pasco, Peru, 2012] — Padial et al. 2014, p. 124; Chávez et al. 2015, p. 18, 21, 22; De la Riva et al. 2017, p. 31; Lehr \& Rodríguez 2017, p. 333, 338; Rodríguez \& Catenazzi 2017, p. 383, 390, 399, 402, 403, Table 2.

Duellman and Hedges (2008) described Phrynopus tribulosus based on a single male collected in 1987, Chaparro et al. (2008) described $P$. nicoleae based on a single female collected in 2007, and Lehr et al. (2012) described P. curator based on a single female collected in 2012.

Phrynopus tribulosus is known from three localities and an elevation from 2600 to $3589 \mathrm{~m}$. Even though Chaparro et al. (2008) and Lehr et al. (2012) compared in their diagnoses the new species with $P$. tribulosus and $P$. nicoleae, sufficient morphological differences were noted to justify the descriptions. Some of the characters mentioned for P. tribulosus by Duellman and Hedges (2008) such as skin on venter smooth (areolate according to Chaparro et al. 2008 and Lehr et al. 2012) or dorsolateral folds absent (elongate dorsolateral warts forming a long discontinuous row that does not fuse to form a fold according to Chaparro et al. 2008, ridges forming discontinuous dorsolateral fold according to Lehr et al. 2012) are likely the result of long storage of the specimen in preservative. Whereas other differences such as absence of dentigerous processes of vomers as noted by Duellman and Hedges (2008) and Lehr et al. (2012) but noted as present by Chaparro et al. (2008) likely reflect intraspecific variation. Singleton species descriptions can be problematic when additional discoveries of specimens are difficult to assign because variation for the species is not covered or the species was not accurately described (see Lim et al. 2012, Köhler and Padial 2016, Lehr and Rodriguez 2017). Therefore, we have updated the species diagnosis of P. tribulosus based on Duellman and Hedges (2008), Chaparro et al. (2008), and Lehr et al. (2012) as follows.

Diagnosis. A species of Phrynopus having the following combination of characters: (1) Skin on dorsum shagreen with small scattered tubercles, middorsum with prominent ridges, often $\mathrm{Y}$ - or $X$-shaped, flanks shagreen with small scattered tubercles, skin on venter weakly areolate; ridges forming discontinuous dorsolateral fold; discoidal fold absent, weak thoracic fold present; (2) tympanic membrane and tympanic annulus absent; (3) snout rounded in dorsal and lateral views; (4) upper eyelid with or without enlarged tubercles; width of upper eyelid narrower than IOD; cranial crests absent; (5) dentigerous processes of vomers present or absent; (6) vocal slits and nuptial pads absent; (7) Finger I shorter than or equal to Finger II; tips of digits rounded; (8) fingers without lateral fringes; (9) ulnar tubercles absent; (10) heel with a distinct conical tubercle; inner tarsal fold absent; outer edge of tarsus with row of subconical tubercles; (11) outer metatarsal tubercle rounded, larger or equal in size of ovoid inner metatarsal tubercle; supernumerary plantar tubercles weakly defined; (12) toes without lateral fringes; basal webbing absent; Toe V slightly shorter or equal to Toe III; toe tips rounded, about as large as those on fingers; (13) in life, dorsum green with brown markings, tan with black irregular stripes and bluish-gray tubercles or reddish brown with dark gray and yellowish-brown mottling; venter gray, marmorated with small, brown, tan and metallic blue blotches or venter gray with pale gray mottling and brownish-cream flecks around posterior half of belly; groin with dark brown blotch, tan with abundant bluish-white spots and an orange spot or groin brown and gray mottled; (14) SVL in single male $15.2 \mathrm{~mm}$, in females 20.7-21.2 $(\mathrm{n}=2) \mathrm{mm}$. 
507

508

509

510

511

512

513

514

515

516

517

518

519

520

521

522

523

524

525

526

527

528

529

530

531

532

533

534

535

536

537

538

539

540

541

542

543

544

545

546

547

548

549

550

551

552

\section{Discussion}

We inferred a molecular phylogeny of Phrynopus and found that two nominal species, Phrynopus curator and Phrynopus nicoleae are junior synonyms of Phrynopus tribulosus. All three nominal taxa are found in the montane forest and Andean grassland of Pasco region, in sites located $30-50 \mathrm{~km}$ from each other. The elevational range of $P$. tribulosus was updated as a result of this taxonomic change. Therefore, the currently known elevational distribution of $P$. tribulosus ranges from 2600 to $3589 \mathrm{~m}$. The high genetic similarity between $P$. nicoleae and $P$. tribulosus was originally identified by De la Riva et al. (2017), but no formal taxonomic action was proposed. Considering the new evidence, we synonymized both $P$. curator and $P$. nicoleae under P. tribulosus.

We identified a single evolutionary transition that involved the loss of both the tympanic membrane and tympanic annulus (Figure 1). Within Phrynopus, only three species exhibit both a tympanic membrane and tympanic annulus. These species, $P$. auriculatus, $P$. peruanus, and an undescribed species that is sister to $P$. peruanus, represent lineages that diverged from the rest early on in the evolutionary history of the group. Previous studies (Lehr 2007, Duellman \& Lehr 2009) had suggested that $P$. montium exhibits a tympanic annulus (visible beneath the skin), although this was not specified in the original description of this species (Shreve 1938). Additionally, inspection of recently collected material from the type locality showed that no tympanic annulus and no tympanic membrane are present in this species (von May 2017). Inspection of X-ray $\mu \mathrm{CT}$ images of the skull of $P$. montium showed that the columella has been completely lost in Phrynopus montium. This result supports the general prediction of Pereyra et al. (2016) that the absence of columella implies the absence of both the tympanic membrane and tympanic annulus, and also corroborates a recent study confirming the absence of tympanic annulus in P. montium (von May 2017).

The absence of tympanic middle ear structures in most species of Phrynopus is correlated with the absence of advertisement calls or other vocalizations in members of this clade. To date, the only species known to produce advertisement calls are $P$. auriculatus, $P$. peruanus, and Phrynopus spI (Duellman \& Lehr 2009; E. Lehr and R. von May, personal observations). Thus, given that most species of Phrynopus do not produce calls and lack the tympanic membrane and annulus, their communication mechanism remains unknown. Taking into account the ideas proposed by Endler (1993), the loss of the tympanic middle ear (sensory system) and advertisement calls (communication signal) in $>90 \%$ of species of Phrynopus may have resulted in the development of a new mode of communication. It is possible that earless species of Phrynopus may have evolved a very different signal structure (e.g., chemical signals) and sensory system (e.g., olfactory) from that observed in most other anuran taxa. Some anurans rely on either chemical or visual signals for conspecific communication, and there is evidence that some groups developed modified olfactory structures to detect chemical signals in the environment (Belanger \& Corkum 2009). Aquatic pheromone communication in anurans has been documented in several species of at least four families (Ascaphidae, Asay et al. 2005; Hylidae, Wabnitz et al. 1999; Leptodactylidae, King et al. 2005; Pipidae, Rabb \& Rabb 1963, Pearl et al. 2000). Knowledge about chemosensory communication in anurans that are primarily terrestrial is more limited. A potentially valuable research direction may be to examine the development of the vomeronasal organ in terrestrial breeding frogs, which is linked to the 
553

554

555

556

557

558

559

560

561

562

563

564

565

566

567

568

569

570

571

572

573

574

575

576

577

578

579

580

581

582

583

584

585

586

587

588

589

590

591

592

593

594

595

596

597

598

olfactory system (Jermacowickz et al. 2004).

We identified several species pairs where one species inhabits the Andean grassland and the other montane forest, suggesting that habitat shifts may be correlated with shifts in elevational distribution. As suggested by studies focusing on ecological gradients (e.g., Schluter 2001), these shifts may reflect differences in selection pressures between montane forest and Andean grassland. However, additional data (i.e., more species pairs) are needed to formally test this hypothesis.

We were interested in examining the relationship between body size and elevation in terrestrial breeding frogs because it had been suggested that larger body size in terrestrial breeding frogs might be common in high-elevation habitats (Hedges et al. 1999, Gonzalez-Voyer et al. 2011), yet the evidence was very limited. We also wanted to examine the relationship because the large majority of amphibians analyzed to date do not follow Bergmann's rule (Adams \& Church 2007). However, previous studies showing no thermal body size cline in anurans (Ashton 2002, Ashton 2004, Schäuble 2004, Adams \& Church 2007) primarily focused on temperate taxa and did not include any strabomantids, a group containing over 700 species. Our finding of a body size cline along elevation in Phrynopus is consistent with Bergmann's rule, which predicts that organisms tend to be larger in colder climates (Bergman 1847, Mayr 1956), and corroborates previous findings showing this pattern in some species of terrestrial breeding frogs (Hedges et al. 1999, Gonzalez-Voyer et al. 2011) and other amphibian taxa (Ashton 2002, Schäuble 2004). It is also worth noticing that not all strabomantid frogs may follow the observed trend of increasing body size with increasing elevation, because some high-elevation species (e.g., Noblella pygmaea) are among the smallest terrestrial vertebrates in the Andes (Lehr \& Catenazzi 2009).

Our findings suggest that ecomorphology in Phrynopus varies across elevation. Our analyses of a phylogenetic PCA (phylomorphospace) support the hypothesis that species living in Andean grassland exhibit a phenotype that is different than that of species living in montane forest or species found in both habitats. Our tests using phylogenetic generalized linear regression models suggest that species living at higher elevations tend to have larger body size than those distributed at lower elevations. Additionally, species living at higher elevations tend to develop shorter limbs, shorter head, and shorter snout than those living at lower elevations. All tested relationships were significant both when controlling for phylogeny under the lambda transform model and also under pure OLS regression, and OLS was the best-supported model in five cases. Yet, some relationships were not significant under the Brownian motion model (Table 3). It has been suggested that the proportional reduction of limb length in some species of terrestrial breeding frogs is related, at least in part, to the primary mode of locomotion (Duellman \& Lehr 2009). Our own observations of locomotion of field-captured species of Phrynopus, as well as several other high-elevation strabomantids (e.g., Bryophryne, Noblella), indicate that they primarily walk, as opposed to hop or jump (E. Lehr and R. von May, personal observations; Duellman \& Lehr 2009); and only one species (P. horstpauli) is arboreal (Lehr et al. 2000). However, given that most species of Phrynopus move primarily by walking, and considering that most of species use similar microhabitats along different elevations (i.e., moss and root mats in montane forest; moss and bunchgrass in Andean grassland) it is unlikely that locomotion is the main factor underlying the observed cline in body shape at different elevations. 
599

600

601

602

603

604

605

606

607

608

609

610

611

612

613

614

615

616

617

618

619

620

621

622

623

624

625

626

627

628

629

630

631

632

633

634

635

636

637

638

639

640

641

642

643

644

\section{Conclusions}

This study develops our understanding about the links between ecological divergence and morphological diversity of a group of Neotropical frogs that belong to the most diverse amphibian family in the Tropical Andes. Although most Strabomantidae have tympanic middle ear, members of different genera living at high elevations have experienced the loss of tympanic membrane and tympanic annulus (Duellman \& Lehr 2009). Given that the group contains 10\% of the world's amphibian species, further studies including additional eared and earless taxa will reveal how many independent losses of the tympanic middle ear have occurred in this large radiation. Additionally, we documented a significant pattern of increasing body size and changes in body shape with increasing elevation. The body size cline has been observed in several terrestrial breeding frogs and other amphibian taxa, although some authors have suggested that most amphibians do not follow Bergmann's rule (Ashton 2002, Ashton 2004, Schäuble 2004, Adams \& Church 2007). We believe that one reason for this discrepancy is that tropical amphibians were largely underrepresented in previous studies, which primarily focused on temperate taxa. Terrestrial breeding frogs are amenable for testing hypotheses such as Bergmann's rule, because of several reasons, including high species diversity and broad elevational distribution. Given that previous tests have included amphibian taxa distributed over narrower elevational gradients, further studies should include additional clades of terrestrial breeding frogs to examine Bergmann's rule predictions. Integrating trait data such as the loss of tympanic middle ear and the loss of advertisement calls with eco-morphological data will shed light on the potential causes and ecological consequences of earlessness in Neotropical terrestrial breeding frogs. Studies that link habitat use, topography, phylogenetic history, and trait divergence will be key for explaining the elevational gradient of species diversity in tropical mountains.

\section{Acknowledgments}

Jesús H. Córdova kindly provided a loan of specimens from the Museo de Historia Natural, Universidad Nacional Mayor de San Marcos, Lima, Peru, and Juan Carlos Cusi provided additional support at the museum. We thank Lydia Smith and the Evolutionary Genomics Laboratory at the Museum of Vertebrate Zoology (UC Berkeley) for facilitating molecular laboratory work. We thank Michelle Lynch and Erin Westeen for their help in generating $\mu C T$ images included in this paper. We thank J. Mitchell for providing some of the scripts used in the analyses, and the members of the Rabosky Lab for providing helpful comments and suggestions. We also thank two anonymous reviewers for providing constructive and helpful comments on the manuscript.

\section{References}

Adams, D.C. and J.O. Church. 2007. Amphibians do not follow Bergmann's rule. Evolution 622: $413-420$.

AmphibiaWeb. 2017. Amphibia Web. Information on amphibian biology and conservation. http://amphibiaweb.org/ [accessed 05 October 2017]. 
645 Antonelli, A., Nylander, J.A.A., Persson, C. and I. Sanmartín. 2009. Tracing the impact of the 646 Andean uplift on Neotropical plant evolution. Proceedings of the National Academy of Sciences 647 of the United States of America 106: 9749-9754.

648

649 Arbogast, B.S., Edwards, S.V., Wakeley, J., Beerli, P. and J.B. Slowinski. 2002. Estimating

650

651

652

653

654

662

663

664

665

666

667

668

669

670

671

672

673

674

675

676

677

678

679

680

681

682

683

684

685

686

687

688

689 divergence times from molecular data on phylogenetic and population genetic timescales. Annual Review of Ecology and Systematics 33: 707-740.

Asay, M.J., Harowicz, P.G. and L. SU. 2005. Chemically mediated mate recognition in the Tailed Frog (Ascaphus truei). In: R.T. Mason, M.P. LeMaster, and D. Müller-Schwarze (eds.), Chemical Signals in Vertebrates 10, pp. 24-31. Springer, New York.

Ashton, K.G. 2002. Do amphibians follow Bergmann's rule? Canadian Journal of Zoology 80: 708-716.

Ashton, K.G. 2004. Sensitivity of intraspecific latitudinal clines of body size for tetrapods to sampling, latitude and body size. Integrative Comparative Biology 44: 403-412.

Belanger, R.M. and L.D. Corkum. 2009. Review of aquatic sex pheromones and chemical communication in anurans. Journal of Herpetology 43(2): 184-191.

Bergmann, C. 1847. Über die Verhältnisse der Wärmeökonomie der Thiere zu ihrer Größe. Göttingen Studien 1: 595-708.

Biomatters. 2013. Geneious R6, version 6.1.5 (http://www.geneious.com/)

Boistel, R., Aubina, T., Cloetensd, P., Peyrind, F., Scottif, T., Herzog, P., Gerlachg, J., Polleth, N. and J.-F. Aubry. 2013. How minute sooglossid frogs hear without a middle ear. Proceedings of the National Academy of Sciences 110: 15360-15364.

Bossuyt, F. and M.C. Milinkovitch. 2000. Convergent adaptive radiations in Madagascan and Asian ranid frogs reveal covariation between larval and adult traits. Proceedings of the National Academy of Sciences of the United States of America 97: 6585-6590.

Boughman, J.W. 2002. How sensory drive can promote speciation. Trends in Ecology and Evolution 17: 571-577.

Catenazzi, A., Lehr, E. and Vredenburg, V.T. 2014. Thermal physiology, disease and amphibian declines in the eastern slopes of the Andes. Conservation Biology 28: 509-517.

Chávez, G., Santa-Cruz, R., Rodríguez, D. and E. Lehr. 2015. Two new species of frogs of the genus Phrynopus (Anura: Terrarana: Craugastoridae) from the Peruvian Andes. Amphibian and Reptile Conservation 9: 15-25. (e105)

690

De la Riva, I., Chaparro, J.C., Castroviejo-Fisher, S. and J.M. Padial. 2017. Underestimated anuran radiations in the high Andes: five new species and a new genus of Holoadeninae, and 
691 their phylogenetic relationships (Anura: Craugastoridae). Zoological Journal of the Linnean

692 Society XX: 1-44.

693

694

695

696

697

698

699

700

701

702

703

704

705

706

707

708

709

710

711

712

713

714

715

716

717

718

719

720

721

722

723

724

725

726

727

728

729

730

731

732

733

734

735

736

Drummond, A.J. and A. Rambaut. 2007. BEAST: Bayesian evolutionary analysis by sampling trees. BMC Evolutionary Biology 7: 214.

Duellman, W.E. and E. Lehr. 2009. Terrestrial-breeding Frogs (Strabomantidae) in Peru. Natur und Tier Verlag, Münster. 382 pp.

Endler, J.A. 1993. Some general comments on the evolution and design of animal communication systems. Philosophical Transactions of the Royal Society London B: Biological Sciences 340(1292): 215-225.

Gonzalez-Voyer, A., Padial, J.M., Castroviejo-Fisher, S., De la Riva, I. and C. Vila. 2011. Correlates of species richness in the largest Neotropical amphibian radiation. Journal of Evolutionary Biology 24: 931-942.

Gregory-Wodzicki, K.M. 2000. Uplift history of the Central and Northern Andes: A review. Geological Society of America Bulletin 112: 1091-1105.

Hedges, S.B. 1990. A new species of Phrynopus (Anura: Leptodactylidae) from Peru. Copeia 1990: 108-112.

Hedges, S.B. 1999. Distribution patterns of amphibians in the West Indies. In: Regional Patterns of Amphibian Distribution: A Global Perspective. Duellman, W.E. (ed.), pp. 211-254. Johns Hopkins University Press, Baltimore, MD.

Hedges, S.B., Duellman, W.E. and M. Heinicke. 2008. New world direct-developing frogs (Anura: Terrarana): molecular phylogeny, classification, biogeography, and conservation. Zootaxa 1737: 1-182.

Hetherington, T.E. and E.D. Lindquist. 1999. Lung-based hearing in an "earless" anuran amphibian. Journal of Comparative Physiology A 184(4): 395-401.

Ho, L.S.T. and C. Anné. 2014a. A linear-time algorithm for Gaussian and non-Gaussian trait evolution models. Systematic Biology 63: 397-408.

Ho, L.S.T. and C. Anné. 2014b. Phylolm: phylogenetic linear regression. R package version 2.1. http://cran.r-project.org/ web/packages/phylolm/ (accessed July 2015).

Huelsenbeck, J.P., Nielsen, R. anb J.P Bollback. 2003. Stochastic mapping of morphological characters. Systematic Biology 52: 131-158.

Irestedt, M., Fjeldså, J., Dalén, L. and P.G.P. Ericson. 2009. Convergent evolution, habitat shifts and variable diversification rates in the ovenbird-woodcreeper family (Furnariidae). BMC Evolutionary Biology 9: 268. 
737

738

739

740

741

742

743

744

745

746

747

748

749

750

751

752

753

754

755

756

757

758

759

760

761

762

763

764

765

766

767

768

769

770

771

772

773

774

775

776

777

778

779

780

781

782

Jaslow, A.P., Hetherington, T.E. and R.E Lombard. 1988. Structure and function of the amphibian middle ear. In The evolution of the amphibian auditory system (Eds. Fritzsch, B. et al.) Ch. 2, pp. 69-91. Wiley.

Jermakowicz, W.J., Dorsey, D.A., Brown, A.L., Wojciechowski, K., Giscombe, C.L., Graves, B.M, Summers, C.H., and G.R. Ten Eyck. 2004. Development of the nasal chemosensory organs in two terrestrial anurans: the directly developing frog, Eleutherodactylus coqui (Anura: Leptodactylidae), and the metamorphosing toad, Bufo americanus (Anura: Bufonidae). Journal of Morphology 261: 225-248.

King, J.D., Rollins-Smith, L.A., Nielsen, P.F., John, A and J.M. Conlon. 2005. Characterization of a peptide from skin secretions of male specimens of the frog, Leptodactylus fallax that stimulates aggression in male frogs. Peptides 26: 597-601.

Köhler, J. and J.M. Padial. 2016. Description and phylogenetic position of a new (singleton) species of Oreobates Jiménez de La Espada, 1872 (Anura: Craugastoridae) from the Yungas of Cochabamba, Bolivia. Annals of Carnegie Museum 84: 23-38.

Lanfear, R., Calcott, B., Ho, S.Y.W. and S. Guindon. 2012. PartitionFinder: Combined Selection of Partitioning Schemes and Substitution Models for Phylogenetic Analyses. Molecular Biology and Evolution 29: 1695-1701.

Lehr, E. 2007. Rediscovery of Phrynopus peruanus Peters 1874 (Amphibia, Anura, Leptodactyidae). Zootaxa 1485: 51-57.

Lehr, E. 2007. New eleutherodactyline frogs (Leptodactylidae, Pristimantis, Phrynopus) from Peru. Bulletin of the Museum of Comparative Zoology 159: 145-178.

Lehr, E., Köhler, G. and E. Ponce. 2000. A new species of Phrynopus from Peru (Amphibia, Anura, Leptodactylidae). Senckenbergiana Biologica 80: 205-212.

Lehr, E. and C. Aguilar. 2002. A new species of Phrynopus (Amphibia, Anura, Leptodactylidae) from the puna of Maraypata (Departamento de Huánuco, Peru). Zoologische Abhandlungen Museum für Tierkunde Dresden 52: 57-64.

Lehr, E., Aguilar, C. and G. Köhler. 2002a. Two sympatric new species of Phrynopus (Anura: Leptodactylidae) from a cloud forest in the Peruvian Andes. Journal of Herpetology 36: 208216.

Lehr, E., Aguilar, C. and J.H. Córdova. 2002b. Morphological and ecological remarks on Phynopus kauneorum (Amphibia, Anura, Leptodactylidae). Zoologische Abhandlungen Museum für Tierkunde Dresden 52: 71-75.

Lehr, E., Lundberg, M. and C. Aguilar. 2005a. Three new species of Phrynopus from central Peru (Amphibia: Anura: Leptodactylidae). Copeia 2005: 479-491. 
783

784

785

786

787

788

789

790

791

792

793

794

795

796

797

798

799

800

801

802

803

804

805

806

807

808

809

810

811

812

813

814

815

816

817

818

819

820

821

822

823

824

825

826

827

828

Lehr, E., Fritzsch, G. and A. Müller. 2005b. Analysis of Andes frogs (Phrynopus, Leptodactylidae, Anura) phylogeny based on $12 \mathrm{~S}$ and $16 \mathrm{~S}$ mitochondrial rDNA sequences. Zoologica Scripta 34: 593-603.

Lehr, E. and A. Catenazzi. 2009. A new species of minute Noblella (Anura: Strabomantidae) from southern Peru: The smallest frog of the Andes. Copeia: 148-156.

Lehr E., Moravec, J. and J.C. Cusi. 2012. Two new species of Phrynopus (Anura, Strabomantidae) from high elevations in the Yanachaga-Chemillén National park in Peru (Departamento de Pasco). ZooKeys 235, 51-71.

Lehr, E. and A. Oróz. 2012. Two new species of Phrynopus (Anura: Strabomantidae) from the Cordillera de Carpish in central Peru (Departamento de Huánuco). Zootaxa 3512, 53-63.

Lehr, E. and D. Rodriguez. 2017. Two new species of Andes Frogs (Craugastoridae: Phrynopus) from the Cordillera de Carpish in central Peru. Salamandra 53(3):327-338.

Lehr, E. and R. von May. 2017. A new species of terrestrial-breeding frog (Amphibia, Craugastoridae, Pristimantis) from high elevations of the Pui Pui Protected Forest in central Peru. ZooKeys 660, 17-42.

Lehr, E., von May, R., Moravec, J. and J.C. Cusi. 2017. A new species of Phrynopus (Amphibia, Anura, Craugastoridae) from upper montane forests and high Andean grasslands of the Pui Pui Protected Forest in central Peru. ZooKeys 713: 131-157

Lim, G.S., Balke, M. and R. Meier. 2012. Determining species boundaries in a world full of rarity: singletons, species delimitation methods. Systematic Biology 61: 165-169.

Mason, M.J., Segenhout, J.M., Cobo-Cuan, A., Quinõnes, P.M. and P. vanDijk. 2015. The frog inner ear: picture perfect? Journal of the Association for Reserach in Otolaryngology 16: 171188.

Mayr, E. 1956. Geographic character gradients and climatic adaptation. Evolution 10:105-108.

Meyer C.P., Geller J.B. and G. Paulay. 2005. Fine scale endemism on coral reefs: archipelagic differentiation in turbinid gastropods. Evolution 59: 113-125.

Moritz, C., Patton, J.L., Schneider, C.J., and T.B. Smith. 2000. Diversification of rainforest faunas: an integrated molecular approach. Annual Review of Ecology and Systematics 31: 533563.

Navas, C.A. 2005. Patterns of distribution of anurans in high Andean tropical elevations: Insights from integrating biogeography and evolutionary physiology. Integrative Comparative Biology 46: 82-91. 
829 Padial, J.M., Grant, T. and D.R. Frost. 2014. Molecular systematics of terraranas (Anura:

830 Brachycephaloidea) with an assessment of the effects of alignment and optimality criteria.

831 Zootaxa 3825: 1-132.

832

833

Palumbi, S.R., Martin, A., Romano, S., McMillan, W.O., Stice, L. and G. Grabowski. 1991. The

834 simple fool's guide to PCR, version 2.0. Privately published document compiled by S. Palumbi,

835

836

837

838

839

840

841

842

843

844

845

846

847

848

849

850

851

852

853

854

855

856

857

858

859 Dept. Zoology, Univ. Hawaii, Honolulu.

Paradis, E., Claude, J. and K. Strimmer. 2004. APE: analyses of phylogenetics and evolution in R language. Bioinformatics 20: 289-290.

Pearl, C.A., Cervantes, M., Chan, M., Ho, U., Shoji, R. and E.O. Thomas. 2000. Evidence for a mate-attracting chemosignal in the dwarf African Claw Frog Hymenochirus. Hormones and Behavior 38: 67-74.

Pereyra, M.O., Womack, M.C., Sebastián Barrionuevo, J., Blotto, B.L., Baldo, D., Targino, M., Ospina-Sarria, J.J., Guayasamin, J.M., Coloma, L.A., Hoke, K.L., Grant, T. and J. Faivovich. 2016. The complex evolutionary history of the tympanic middle ear in frogs and toads (Anura). Scientific Reports 6: 34130

Peters, W.C.H. 1873. Über zwei Gisftschlangen aus Afrika und über neue oder weniger bekannte Gattungen und Arten von Batrachiern. Monatsberichte der Königlichen Preussische Akademie der Wissenschaften zu Berlin 1873: 411-418.

Rabb, G.B. and M.S. Rabb. 1963a. Additional observations on breeding behavior of the Surinam toad Pipa. Copeia 1963: 636-642.

Rambaut, A. and A.J. Drummond. 2007. Tracer. Version 1.5. Available at:

http://tree.bio.ed.ac.uk/software/tracer/.

860

Rheindt, F.E., Christidis, L. and J.A. Norman. 2008. Habitat shifts in the evolutionary history of 861

862

863

864

865

866

867

868

869

870

871

872

873 a Neotropical flycatcher lineage from forest and open landscapes. BMC Evolutionary Biology 8: 193.

Revell, L.J. 2009. Size-correction and principal components for interspecific comparative studies. Evolution 63: 3258-3268.

Revell, L.J. 2012. phytools: an R package for phylogenetic comparative biology (and other things). Methods Ecology and Evolution 3: 217-223.

Rodríguez, L.O. and A. Catenazzi. 2017. Four new species of terrestrial-breeding frogs of the genus Phrynopus (Anura: Terrarana: Craugastoridae) from Río Abiseo National Park, Peru. Zootaxa 4273 (3): 381-406.

874

Ronquist, F. and , J.P Huelsenbeck. 2003. MrBayes 3: Bayesian phylogenetic inference under mixed models. Bioinformatics 19: 1572-1574. 
875

876

877

878

879

880

881

882

883

884

885

886

887

888

889

890

891

892

893

894

895

896

897

898

899

900

901

902

903

904

905
Schäuble, C.S. 2004. Variation in body size and sexual dimorphism across geographical and environmental space in the frogs Limnodynastes tasmaniensis and L. peronii. Biological Journal of the Linnaean Society 82: 39-56.

Schluter, D. 2001. Ecology and the origin of species. Trends in Ecology and Evolution 16: 372380 .

Smirnov, S.V. 1991. The anuran middle ear: developmental heterochronies and adult morphology diversification. Belgian Journal of Zoology 121: 99-110.

Trueb, L. and E. Lehr. 2008. A new species of Phrynopus (Anura, Strabomantidae) from Peru, with comments on the osteology of the genus. Phyllomedusa 7: 11-24.

von May, R. 2017. Rediscovery of the Endangered frog Phrynopus montium (Shreve, 1938) (Amphibia, Anura, Craugastoridae) in the cloud forest of central Peru. Zootaxa 4338(1): 195200.

von May, R., Catenazzi, A., Corl, A., Santa-Cruz, R., Carnaval, A.C. and C. Moritz. 2017. Divergence of thermal physiological traits in terrestrial breeding frogs along a tropical elevational gradient. Ecology and Evolution 7: 3257-3267.

Vorobyeva, E. and S. Smirnov. 1987. Characteristic features in the formation of anuran soundconducting systems. Journal of Morphology 192: 1-11.

Wabnitz, P.A., Bowie, J.H., Tyler, M.J., Wallace, J.C. and B.P. Smith. 1999. Aquatic sex pheromone from a male tree frog. Nature 401: 444-445.

Womack, M.C., Christensen-Dalsgaard, J., Coloma, L.A., Chaparro, J.C. and K.L. Hoke. 2017. Earless toads sense low frequencies but miss the high notes. Proceedings of the Royal Society B 284: 20171670. 


\section{Figure 1}

Frog photo

Adult female of Phrynopus peruanus MUSM 30912 collected at the type locality in central

Peru. Notice the presence of tympanum and the relatively short limbs and short head compared with other species of Phrynopus. Photographs by R. von May.

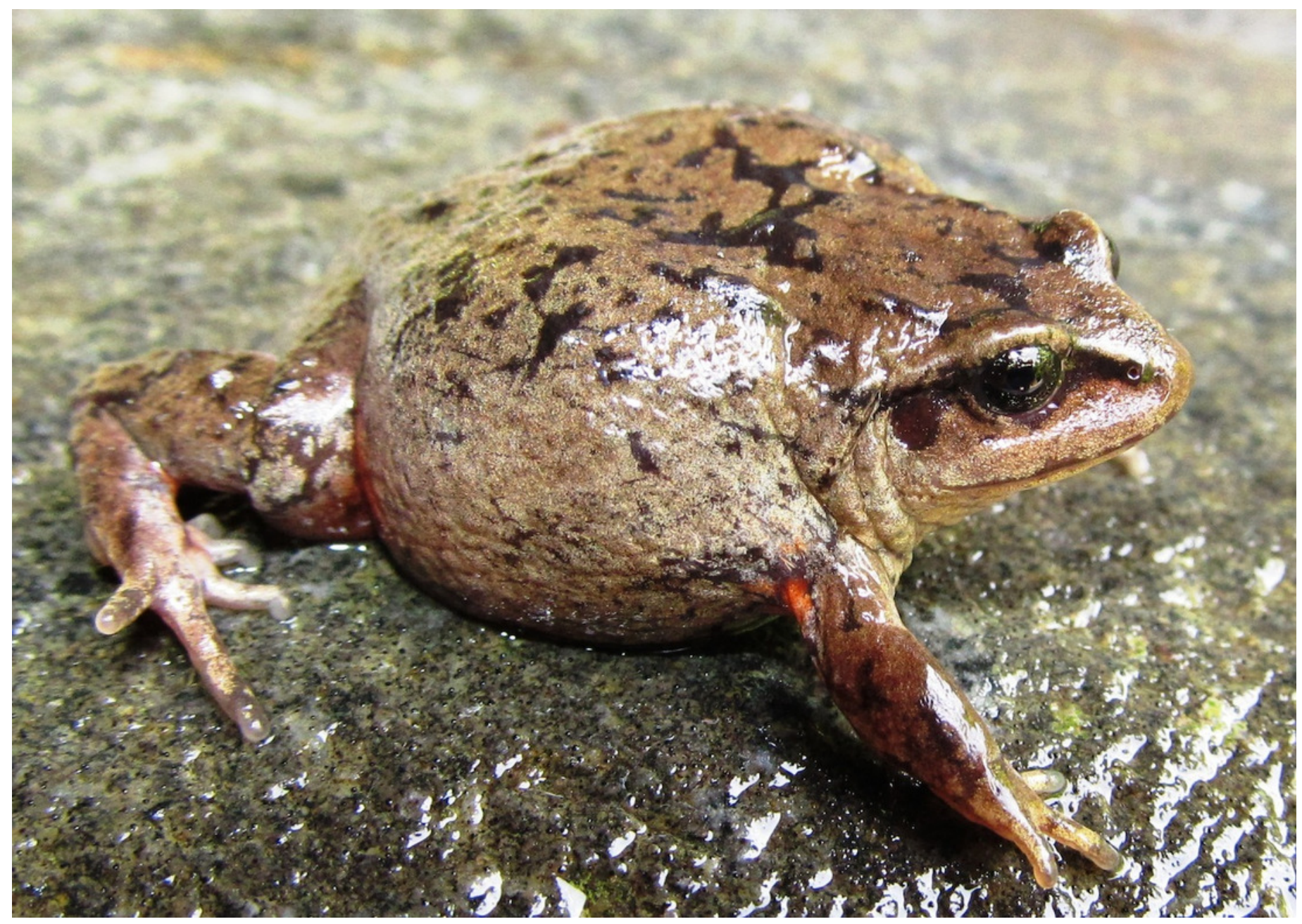


Figure 2 (on next page)

CT scan images

Three-dimensional reconstructions based on $\mu \mathrm{CT}$ data, from the skull and middle ear structures in "eared" and "earless" frogs. Dorsal (a), postero-lateral (b) and ventral (c) views of the skull of Phrynopus peruanus MUSM 30912, and the presence of the columella (stapes) indicated in red. Dorsal (d), postero-lateral (e) and ventral (f) views of the skull of Phrynopus montium MUSM 33259; the columella is absent in this species. 
Figure 3 (on next page)

Phylogeny

Bayesian maximum clade-credibility tree for species included in this study based on a 2646bp concatenated partitioned dataset (16S, 12S, COI, RAG1, Tyr) analyzed in MrBayes (posterior probabilities are indicated at each node). The red bar indicates terminals representing Phrynopus tribulosus; two of these were recognized as Phrynopus nicoleae and Phrynopus curator in previous studies (see text for details). 
Phrynopus peruanus RvM25 12

- Phrynopus perdanis RV N/23 12

Phrynopus peruanus RvM21 12

Phrynopus peruanus RvM26 12

1

Phrynopus peruanus RvM24 12

Phrynopus peruanus RvM22 12

Phrynopus peruanus RvM09 12

Phrynopus peruanus EL336

Phrynopus spl RvM60 14

Phrynopus spl RvM59 14

Phrynopus auriculatus MUBI 6471

1 [ Phrynopus auriculatus KU291634

Phrynopus heimorum MTD45622

Phrynopus heimorum MTD45621

$0.99 \_\begin{array}{l}\text { Phrynopus unchog MUSM32749 } \\ \text { Phrynopus unchog MUSM32748 }\end{array}$

1 [ Phrynopus tribulosus MUBI 7166

Phrynopus tribulosus MUBI 6451

Phrynopus nicoleae MUBI 6441

- Phrynopus tribulosus KU291630

Phrynopus curator MUSM31106

1 _ Phrynopus vestigiatus MUSM29542

Phrynopus interstinctus MUSM29543

$1 ـ\left[\begin{array}{l}\text { Phrynopus montium RvM56 } 14 \\ \text { Phrynopus montium RvM54 } 14\end{array}\right.$ Phrynopus juninensis RvM55 14

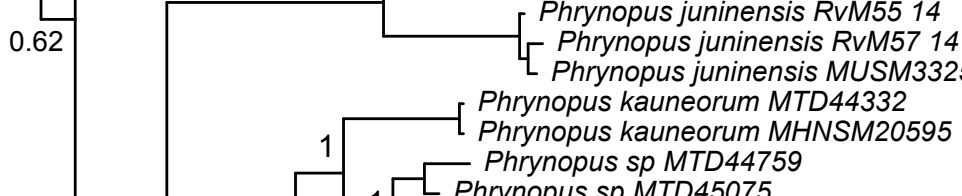

L Phrynopus juninensis MUSM33258

$0.62 \begin{aligned} & \text { Phrynopus juninensis RvM55 } 14 \\ & \text { Phrynopus juninensis RvM57 } 14 \\ & \text { Phrynopus juninensis MUSM33258 } \\ & \text { Phrynopus kauneorum MTD44332 } \\ & \text { Phrynopus kauneorum MHNSM20595 } \\ & \text { Phrynopus sp MTD44759 }\end{aligned}$

0.91

1 Phrynopus inti MUSM31984

$-[$ Phrynopus inti MUSM31976

1

1

0.99

Phrynopus inti MUSM31968

Phrynopus inti NMP6V75584

Phrynopus inti UMMZ 245219

Phrynopus inti UMMZ 245218

Phrynopus inti MUSM31203

Phrynopus miroslawae MUBI 6469

1 Phrynopus tautzorum MHNSM20613

- Phrynopus bufoides MHNSM19860

0.99

0.5211 Phrynopus pesantesi MTD45072

Phrynopus horstpauli MTD44333

Phrynopus barthlenae MHNSM20609

Phrynopus barthlenae SMF81720

1 Phrynopus bracki USNM286919

- Phrynopus badius MUSM31099

- Phrynopus badius FMNH282818

$1 \longrightarrow$ Oreobates gemcare MHNC6687

Oreobates ayacucho MNCN5024

Oreobates granulosus MHNC3396

Oreobates cruralis KU215462

Oreobates amarakaeri MHNC6975

Lynchius simmonsi QZ41639

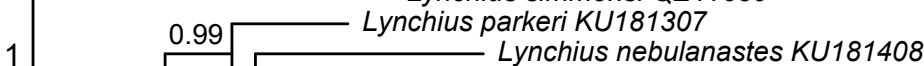

1 - Lynchius oblitus MHNC8652

- Lynchius oblitus MHNC8674

Lynchius oblitus MHSNM19914

Lynchius oblitus MHNC8614

1 Lynchius tabaconas MHNC8650

Lynchius tabaconas MHNC8637

Lynchius flavomaculatus KU218210

Hypodactylus dolops

- Hypodactylus brunneus KU178258 
Figure 4(on next page)

Stochastic mapping tree

Species tree of Phrynopus species included in this study, and representative species of Lynchius and Oreobates, with a sample stochastic character map of tympanum condition (blue indicates presence and orange indicates absence of tympanic annulus) and ancestral state estimates from 500 simmaps indicated at the nodes. 


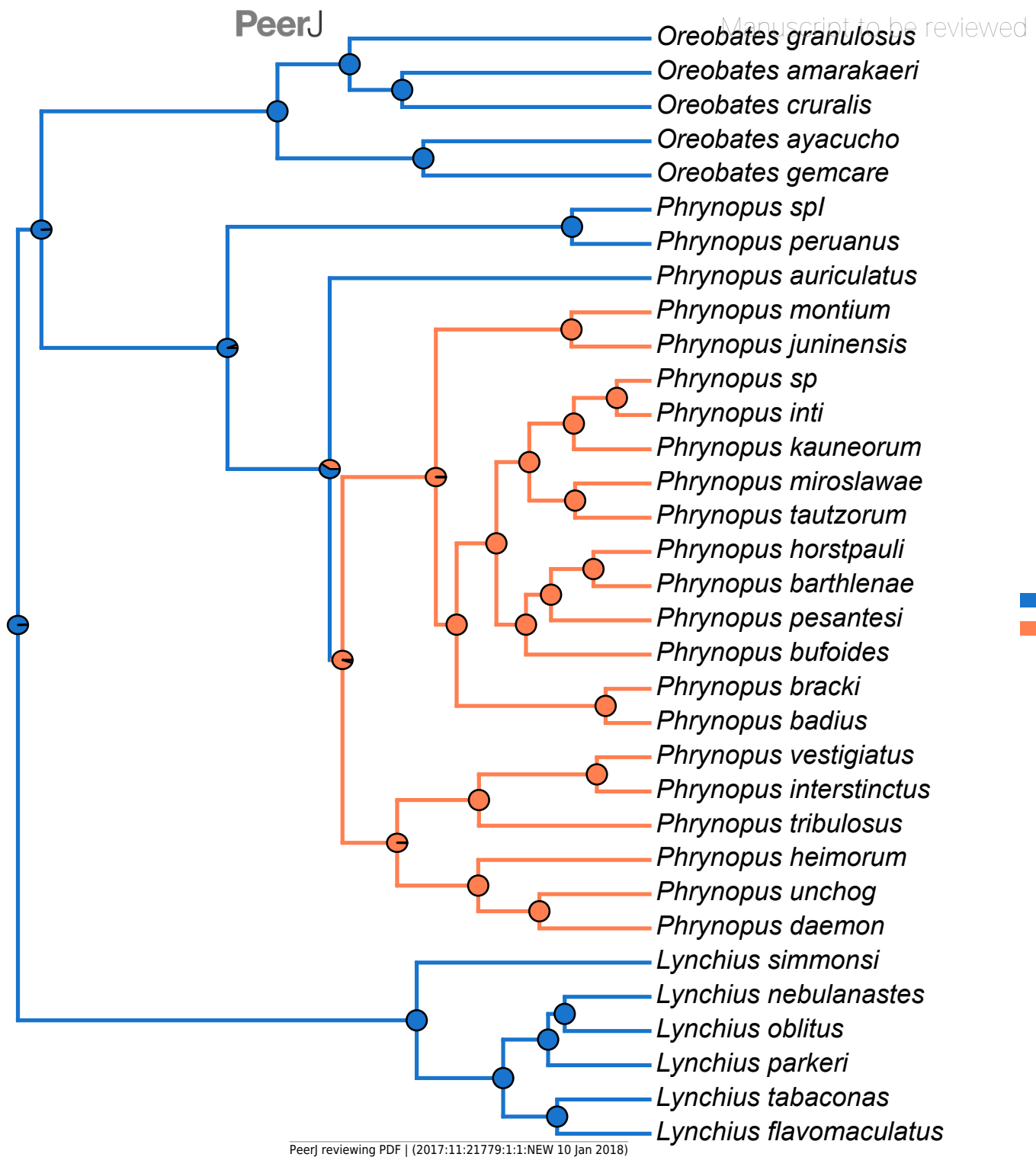

Character state

Tympanum present Tympanum absent 
Figure $\mathbf{5}$ (on next page)

Tree and elevational ranges

Elevational distribution and habitat use are not related to tympanum condition in Phrynopus. The species tree (obtained with *BEAST) depicting the relationship among 22 species of Phrynopus (top) is color-coded according to the presence (blue) or absence (orange) of tympanic membrane and annulus. The elevational ranges (bottom) are color-coded according to species' primary habitat: Andean grassland (yellow), montane forest (dark green), and both habitats (light green). The elevational midpoint is denoted by a black bar. 


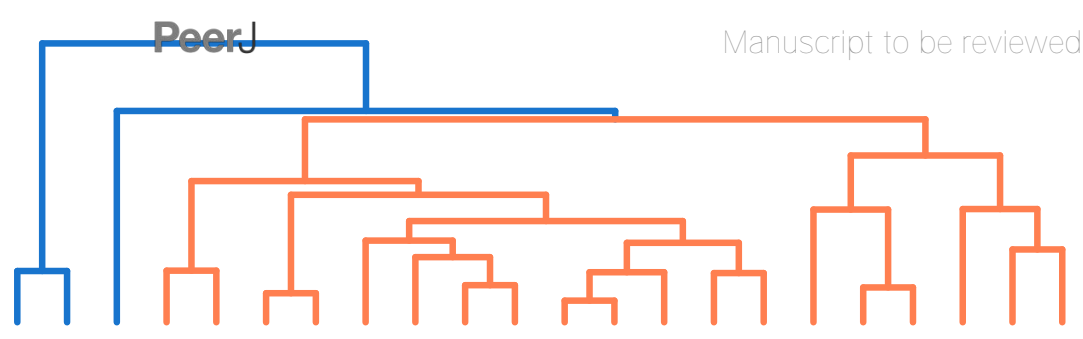

Character state

- Tympanum present

- Tympanum absent
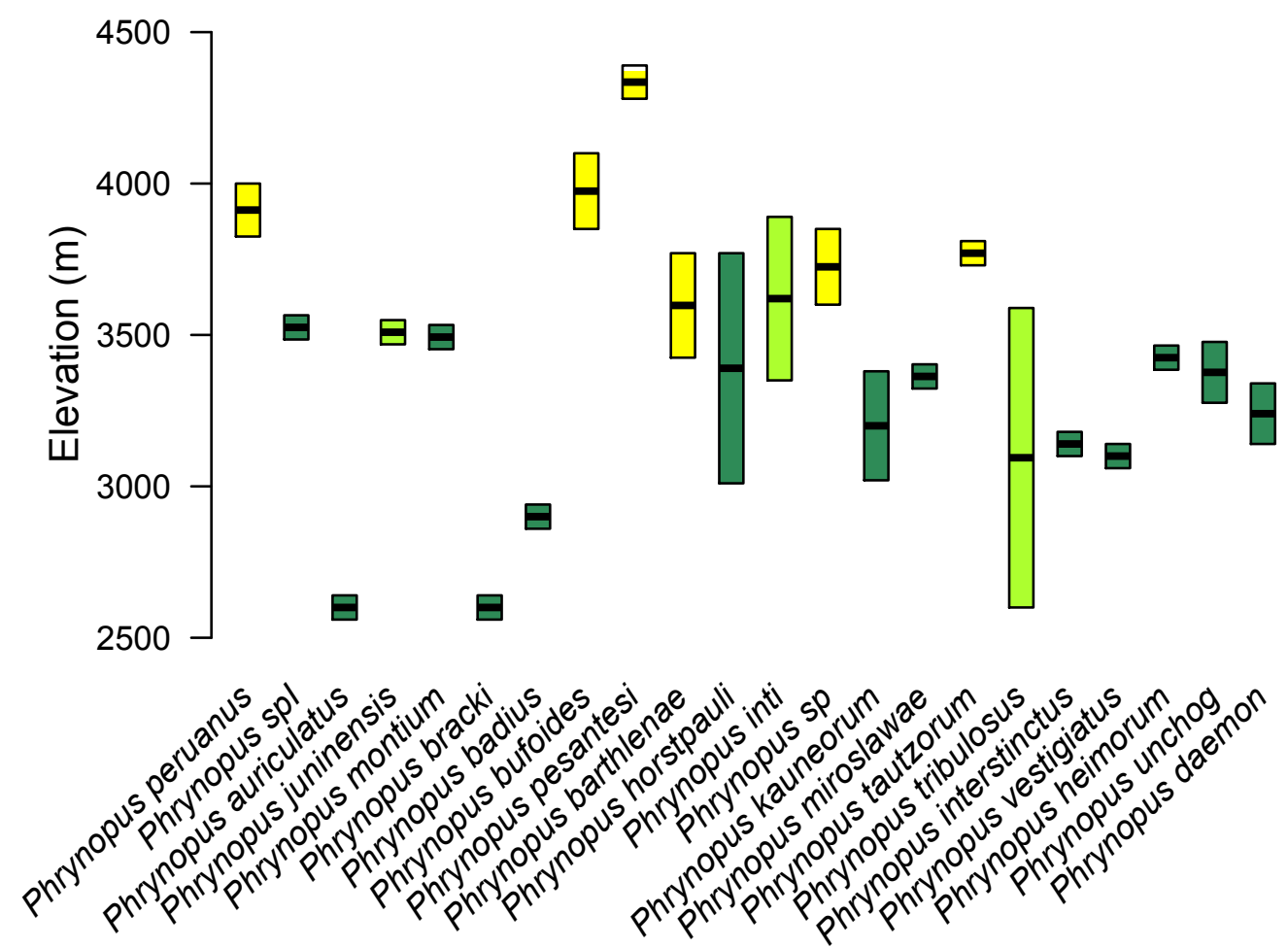
Figure 6 (on next page)

Phylomorphospace

Phylomorphospace projection of Phrynopus species based on body-size corrected data following a phylogenetic size-correction using generalized least-squares (GLS) regression analysis . Body shape in Phrynopus is not associated with tympanum condition (a, b). In contrast, species' body shape appears to be related to habitat: species that inhabit the Andean grassland occupy a smaller region of morphospace than species that live in montane forest $(c, d)$. The full dataset included data from adult males and females $(a, c)$; the reduced dataset included adult females only (b, d). 
Figure 7 (on next page)

Multipanel plot morphology vs elevation

Body size and body shape in Phrynopus vary across elevations. Body size (a) tends to increase with increasing elevation. In contrast, when controlling for body size, species at higher elevations tend to be characterized by shorter limbs (b, c), shorter head (d), shorter snout (e), and narrower snout tips (f) than species living at lower elevations. Species are color-coded according to habitat use: Andean grassland (yellow), montane forest (dark green), and both habitats (light green). The regression lines reflect the phylogenetic correction. Based on dataset containing measurements from adult females only. 


\section{Table $\mathbf{1}$ (on next page)}

PCA loadings full dataset

Loadings for the nine morphological variables from a phylogenetic PCA ran on body-size corrected residuals following a phylogenetic size-correction using GLS regression. The first seven PCs explained $97.5 \%$ of the variance, as estimated using the full dataset (adult males and females). Loadings for the last two PCs not included. 
1 Table 1. Loadings for the nine morphological variables from a phylogenetic PCA ran on body-

2 size corrected residuals following a phylogenetic size-correction using GLS regression. The first 3 seven PCs explained $97.5 \%$ of the variance, as estimated using the full dataset (adult males and

4 females). Loadings for the last two PCs not included.

\begin{tabular}{lccccccc}
\hline Variable & PC1 & PC2 & PC3 & PC4 & PC5 & PC6 & PC7 \\
\hline Tibia length (TL) & -0.447 & 0.189 & 0.146 & -0.105 & 0.283 & -0.154 & -0.263 \\
Foot Length (FL) & -0.407 & 0.285 & -0.085 & -0.397 & 0.163 & 0.210 & -0.338 \\
Head Length (HL) & -0.281 & -0.369 & 0.414 & -0.016 & 0.598 & 0.047 & 0.295 \\
Head Width (HW) & -0.384 & -0.353 & 0.058 & -0.007 & -0.314 & -0.070 & 0.493 \\
Eye Diameter (ED) & -0.218 & -0.155 & -0.706 & 0.508 & 0.323 & 0.253 & -0.002 \\
Interorbital Distance (IOD) & -0.103 & -0.577 & -0.307 & -0.559 & -0.237 & 0.150 & -0.210 \\
Eyelid Width (EW) & -0.334 & -0.110 & 0.388 & 0.470 & -0.432 & 0.368 & -0.390 \\
Internarial Distance (IND) & -0.392 & 0.063 & -0.197 & 0.128 & -0.198 & -0.761 & -0.051 \\
Eye-Nostril Distance (E-N) & -0.290 & 0.500 & -0.123 & -0.151 & -0.224 & 0.352 & 0.536 \\
\% Variance explained & 43.04 & 19.12 & 11.07 & 7.66 & 7.12 & 5.64 & 3.80 \\
\hline
\end{tabular}




\section{Table 2 (on next page)}

PCA loadings females only

Loadings for the nine morphological variables from a phylogenetic PCA ran on body-size corrected residuals following a phylogenetic size-correction using GLS regression. The first seven PCs explained $96.7 \%$ of the variance, as estimated using the reduced dataset (females only). Loadings for the last two PCs not included. 
1 Table 2. Loadings for the nine morphological variables from a phylogenetic PCA ran on body2 size corrected residuals following a phylogenetic size-correction using GLS regression. The first 3 seven PCs explained $96.7 \%$ of the variance, as estimated using the reduced dataset (females 4 only). Loadings for the last two PCs not included.

\begin{tabular}{lccccccc}
\hline Variable & PC1 & PC2 & PC3 & PC4 & PC5 & PC6 & PC7 \\
\hline Tibia length (TL) & -0.461 & 0.122 & -0.138 & -0.051 & -0.348 & -0.187 & -0.441 \\
Foot Length (FL) & -0.451 & 0.200 & 0.226 & 0.022 & -0.242 & -0.438 & -0.014 \\
Head Length (HL) & -0.209 & -0.228 & -0.694 & -0.381 & -0.177 & -0.128 & 0.446 \\
Head Width (HW) & -0.376 & -0.359 & -0.071 & 0.216 & 0.415 & 0.180 & 0.171 \\
Eye Diameter (ED) & -0.135 & -0.386 & 0.459 & -0.542 & -0.348 & 0.451 & -0.012 \\
Interorbital Distance (IOD) & -0.064 & -0.646 & 0.295 & 0.144 & 0.133 & -0.546 & 0.025 \\
Eyelid Width (EW) & -0.313 & -0.162 & -0.137 & 0.622 & -0.292 & 0.447 & -0.066 \\
Internarial Distance (IND) & -0.396 & 0.102 & -0.067 & -0.322 & 0.618 & 0.138 & -0.390 \\
Eye-Nostril Distance (E-N) & -0.350 & 0.401 & 0.349 & 0.025 & 0.101 & 0.062 & 0.649 \\
\% Variance explained & 39.95 & 18.51 & 11.69 & 11.42 & 6.00 & 5.30 & 3.80 \\
\hline
\end{tabular}




\section{Table 3(on next page)}

Phylogenetic generalized linear regression models

Results from phylogenetic generalized linear regression models for SVL and other body sizecorrected variables with respect to elevation. Model fitting was done with morphological data from adult females only (21 species; see Tables 1 and 2 for variable abbreviations). With the exception of SVL, other morphological variables were corrected with respect to body size prior to tests. Bold font indicates significant values. 
1 Table 3. Results from phylogenetic generalized linear regression models for SVL and other body 2 size-corrected variables with respect to elevation. Model fitting was done with morphological 3 data from adult females only ( 21 species; see Tables 1 and 2 for variable abbreviations). With the 4 exception of SVL, other morphological variables were corrected with respect to body size prior 5 to tests. Bold font indicates significant values.

\begin{tabular}{lcccccc}
\hline Model & Evol. model & $\boldsymbol{\lambda}$ & Coefficient & P-value & AIC & logLik \\
& & & & & & \\
SVL $\sim$ Elev. midpoint & OLS & & 0.0092 & $\mathbf{0 . 0 0 1 7}$ & 125.04 & -61.52 \\
SVL $\sim$ Elev. midpoint & BM & & 0.0048 & 0.1203 & 128.84 & -63.42 \\
SVL $\sim$ Elev. midpoint & Lambda & 0.26 & 0.0082 & $\mathbf{0 . 0 0 4 1}$ & 126.68 & -61.34 \\
& & & & & & \\
TL $\sim$ Elev. midpoint & OLS & & $<-0.0001$ & $\mathbf{0 . 0 1 1 6}$ & -73.2 & 37.6 \\
TL $\sim$ Elev. midpoint & BM & & $<-0.0001$ & $\mathbf{0 . 0 3 4 0}$ & -76.46 & 39.23 \\
TL $\sim$ Elev. midpoint & Lambda & 1.00 & $<-0.0001$ & $\mathbf{0 . 0 3 4 0}$ & -74.46 & 39.23 \\
& & & & & & \\
FL $\sim$ Elev. midpoint & OLS & & $<-0.0001$ & $\mathbf{0 . 0 1 8 6}$ & -78.00 & 40.00 \\
FL $\sim$ Elev. midpoint & BM & & $<-0.0001$ & 0.0544 & -74.82 & 38.41 \\
FL $\sim$ Elev. midpoint & Lambda & 0.64 & $<-0.0001$ & $\mathbf{0 . 0 2 5 3}$ & -75.94 & 39.97 \\
& & & & & & \\
HL $\sim$ Elev. midpoint & OLS & & $<-0.0001$ & $\mathbf{0 . 0 3 1 6}$ & -86.36 & 44.18 \\
HL $\sim$ Elev. midpoint & BM & & $<-0.0001$ & 0.2207 & -83.82 & 42.91 \\
HL $\sim$ Elev. midpoint & Lambda & 0.00 & $<-0.0001$ & $\mathbf{0 . 0 3 1 6}$ & -84.36 & 44.18 \\
& & & & & & \\
E-N $\sim$ Elev. midpoint & OLS & & $<-0.0001$ & $\mathbf{0 . 0 0 0 7}$ & -144.18 & 73.09 \\
E-N $\sim$ Elev. midpoint & BM & & $<-0.0001$ & $\mathbf{0 . 0 0 1 4}$ & -138.00 & 70.00 \\
E-N $\sim$ Elev. midpoint & Lambda & 0.00 & $<-0.0001$ & $\mathbf{0 . 0 0 0 7}$ & -142.18 & 73.09 \\
& & & & & & \\
IND $\sim$ Elev. midpoint & OLS & & $<-0.0001$ & $<\mathbf{0 . 0 0 0 1}$ & -146.70 & 74.35 \\
IND $\sim$ Elev. midpoint & BM & & $<-0.0001$ & $<\mathbf{0 . 0 0 0 1}$ & -142.56 & 72.28 \\
IND $\sim$ Elev. midpoint & Lambda & 0.00 & $<-0.0001$ & $<\mathbf{0 . 0 0 0 1}$ & -144.70 & 74.35 \\
\hline
\end{tabular}

